\title{
ÁREAS DA BIOLOGIA: EM QUAIS OS ALUNOS SE SENTEM PREPARADOS?
}

\author{
AREAS OF BIOLOGY: IN WHICH STUDENTS FEEL PREPARED?
}

Adriana Moreira ${ }^{1}$, Renata Fernandes de Matos²*

${ }^{1}$ Universidade Estadual do Ceará

2 Professora do Curso de Ciências Biológicas da UECE/FECLI*renatafmatos@hotmail.com.

Info

Recebido: 04/2021

Publicado: 09/2021

ISSN: $2358-260 X$

\section{Palavras-Chave}

Ensino-aprendizagem.

Interdisciplinaridade. Práticas

pedagógicas.

Teaching-learning. Interdisciplinarity.

Pedagogical practices.
DOI: 10.37951/2358-260X.2021v8i2.5660

Keywords:

\section{Resumo}

As Ciências Biológicas apresentam diversas áreas que podem atrair a atenção dos alunos, fazendo com que estes se dediquem nestas a ponto de se considerarem preparados para atuar como profissionais, sobretudo, quando se considera a formação de professores. Com o objetivo de identificar em quais áreas os alunos se sentem "mais" e "menos" preparados para atuar, desenvolveu-se uma pesquisa do tipo descritiva. Foram entrevistados alunos de um curso de Licenciatura em Ciências Biológicas de uma Instituição de Ensino Superior localizada no interior do estado do Ceará, à qual é um campus pertencente a Universidade Estadual do Ceará. O foco foram os alunos dos dois últimos semestres $\left(8^{\circ}\right.$ e $\left.9^{\circ}\right)$, os quis responderam a um questionário elaborado na plataforma Google Forms, o que ocorreu com posterior análise pelo programa Microsoft Excel 2016, sendo os dados transformados em porcentagens e expressos na forma de tabelas. Pelos resultados identifica-se que as áreas de "maior" preparo são Ecologia, Genética e Zoologia; e nas área de "menor" preparo foi citada, sobretudo, a Botânica. Os resultados levam a concluir que nos cursos de graduação todas as áreas das Ciências Biológicas devem ser igualmente fortalecidas no que diz respeito a construção do conhecimento, devendo os alunos se atentar também ao aspecto pedagógico envolvido nestas.

\begin{abstract}
Biological Sciences have several areas that can attract the attention of students, making them dedicate themselves to them to the point where they consider themselves prepared to act as professionals, especially when considering the training of teachers. In order to identify in which areas students feel "more" and "less" prepared to work, a descriptive research was developed. Students of a Licentiate Degree in Biological Sciences of a Higher Education Institution located in the interior of the state of Ceará, which is a campus belonging to the State University of Ceará, were interviewed. The focus was on the students of the last two semesters (8th and 9th), who answered a questionnaire prepared on the Google Forms platform, which occurred with subsequent analysis by the Microsoft Excel 2016 program, with the data being transformed into percentages and expressed in the form of tables. From the results, it is identified that the areas of "greater" preparation are Ecology, Genetics and Zoology; and in the areas of "minor" preparation, Botany was mentioned above all. The results lead to the conclusion that, in undergraduate courses, all areas of Biological Sciences should be equally strengthened with regard to knowledge construction, and students should also pay attention to the pedagogical aspect involved in these.
\end{abstract}

\section{INTRODUÇÃO}

A construção do conhecimento é um processo que leva o aluno ao desenvolvimento de conclusões a partir do contato com os saberes das mais diversas áreas. Contudo, para isto é necessário que os alunos tenham ciência sobre o nível de dedicação empenhada no período de aquisição de informações, sobretudo, no meio acadêmico. Neste, os alunos contam com a ajuda dos professores não apenas para construir novos conhecimentos, mas também para fazer conexões entre aquilo que já sabem e aquilo que estão aprendendo (ÁBILA, 2010). 
Um aluno bem formado é o resultado de uma educação de qualidade, o que não pode ocorrer se o conhecimento não for o elo de ligação entre os agentes do processo de ensino-aprendizagem (TEIXEIRA, 2010). Diante dessa realidade, torna-se necessário a construção do conhecimento voltado para uma educação comprometida e construtiva, de forma que os alunos possam se aprofundar nas mais diversas áreas de estudo, a ponto de se identificarem e se sentirem preparados para a atuação profissional.

O desempenho acadêmico está ligado diretamente ao ato e ao hábito de estudar, o qual envolve o desenvolvimento de habilidades para lidar com o novo. A performance dos alunos é construída ao longo do tempo, buscando aprofundamentos que levem à formação de profissionais que apresentem elevada competência. Como resultado, o desenvolvimento da capacidade cognitiva de associar a teoria à prática ressalta-se para os alunos como algo que os dá segurança em sua área de aprofundamento (CEVALLOS, 2011).

Quando se considera a formação de professores, unir teoria e prática se torna um fator essencial, devendo a construção dos conhecimentos nessas duas faces ser permeada pelo rigor e pelo carácter sistemático no que diz respeito a abordagem e a compreensão dos fatos e fenômenos. Dessa forma, a profissão docente se caracteriza como a "profissão do conhecimento" e, deste modo, o trabalho docente desenvolve-se com base no compromisso de transformar conhecimentos em aprendizagens (MARCELO, 2009).

As disciplinas cursadas ao longo de um curso de graduação apresentam, nesse contexto, um relevante impacto na formação profissional, tanto no que diz respeito aos conteúdos que fazem parte destas, como na forma com que estas são conduzidas. Para Morin (2014, p. 105), “as disciplinas são categorias organizadoras dentro do conhecimento científico, o que institui a divisão e a especialização do trabalho e responde à diversidade das áreas que as ciências abrangem", sendo, dessa forma, todas de igual importância.

Para que uma disciplina seja bem cursada é necessário que os alunos estejam motivados, praticando ações que os levem a um ganho de percepção e a um aumento de autonomia no que diz respeito à aquisição de informações. Contudo, a ausência de motivação somada a falta de dedicação gera graves consequências para o aprendizado, a ponto de formar alunos que se sentem despreparados para trabalhar em uma determinada área, fazendo com que muitos se sintam incapazes e não sigam com a profissão (PINTO, 2011). Nesse contexto, ao mesmo tempo em que um aluno adquire e produz conhecimentos em uma determina área, o mesmo beneficia e se beneficia de todos os aspectos envolvidos na partilha de suas experiências. Motivar-se para adquirir conhecimentos passa a ser o ponto chave para conhecer as diversas áreas da profissão escolhida e compreender a ligação existente entre essas, o que é essencial, uma vez que trabalhar a interdisciplinaridade levará o indivíduo a construir e reconstruir conhecimentos, a transformar e ser transformado por estes (CHARLOT, 2005).

Apesar dessa integração de conhecimentos, é necessário que o aluno tenha clareza sobre a área que pretende seguir, o que, segundo Morin (2015), é importante porque culturas científicas diferentes por natureza separam as diferentes áreas do conhecimento. Dessa forma, aprender na universidade não pode ser tão somente a repetição mecânica do conhecimento, mas sim uma ação que inclui a flexibilidade de pensamento, a comunicação e a tomada de decisões, o que deve ser vivenciado em cada área de aprendizagem (IMBERNÓN, 2012). 
Diante dessas informações, o presente estudo tem por objetivo identificar as áreas em que os alunos de um curso de Licenciatura Ciências Biológicas se sentem "mais" e "menos" preparados para trabalhar como professores.

\section{MATERIAL E MÉTODOS}

Foi desenvolvida uma pesquisa do tipo descritiva, à qual tem por finalidade observar, registrar e analisar fenômenos ou sistemas técnicos sem que haja a interferência do pesquisador (PRADONOV; FREITAS, 2013). A pesquisa descritiva possibilita realizar a interpretação dos fatos envolvidos na investigação, sendo uma de suas peculiaridades a utilização de técnicas padronizadas de coleta de dados como questionários (BARROS; LEHFELD, 2007).

A pesquisa foi desenvolvida em uma Instituição de Ensino Superior localizada no interior do estado do Ceará, à qual é um campus pertencente à Universidade Estadual do Ceará-UECE. Foram entrevistados alunos do curso de Licenciatura em Ciências Biológicas ofertado pela referida instituição, os quais estavam regulamente matriculados no $8^{\circ}$ e $9^{\circ}$ semestres, uma vez que a pesquisa teve como foco os dois semestres finais do curso, afim de investigar os alunos concludentes.

Os dados foram coletados por meio da aplicação de um formulário elaborado na plataforma Google Forms, o qual foi enviado para o e-mail dos alunos e estes os preencheram de maneira anônima. Essa modalidade de pesquisa foi adotada devido ao ensino ocorrer na modalidade remota, o que é reflexo do isolamento social adotado em decorrência da pandemia da COVID-19.

A aplicação de questionários/formulários possibilita uma categorização descritiva e interpretativa das informações apresentadas pelo público alvo da pesquisa (LAKATOS; MARCONI, 2011). O trabalho com os dados coletados pode assim ser realizado de maneira organizada, facilitando a interpretação e a identificação da realidade vivenciada pelos indivíduos foco da pesquisa.

Após a coleta dos dados, realizou-se a análise dos mesmos com o auxílio do programa Microsoft Excel 2016, o qual é uma ferramenta relevante e eficaz para a organização e análise das informações coletadas. Os dados obtidos foram transformados em porcentagens e os valores apresentados na forma de tabelas, o que teve por finalidade facilitar a interpretação dos resultados.

\section{RESULTADOS E DISCUSSÃO}

A investigação sobre as áreas do curso de Ciências Biológicas para as quais os alunos apontaram se sentir "mais" e "menos" preparados para dar aulas revelam como foi o aprendizado nas disciplinas ao longo do curso. Estes resultados apresentam informações sobre a eficácia do processo de ensinoaprendizagem, pois para que o aluno se sinta preparado para ministram conteúdos de uma determinada área é necessário que o ensino tenha sido realizado com qualidade e o aprendizado com eficiência.

$\mathrm{Na}$ Tabela 1 é possível observar as áreas apontadas como aquelas em que os alunos se sentem "mais" preparados. De uma forma geral, observa-se que diversas áreas foram citadas, o que revela que as Ciências Biológicas atraem e formam alunos nos mais variados campos. As disciplinas que apresentaram maior citação foram Ecologia e Genética, contando com as maiores porcentagens identificadas.

O provável motivo para essas áreas terem sido as mais citadas se associa ao fato das mesmas estarem interligadas com diversas outras áreas dentro do curso. Ao estudar Ecologia, os alunos precisam apresentar conhecimentos sobre áreas como Educação Ambiental, Geociências, Parasitologia e Botânica, o que faz com 
que conhecimentos diversos sejam compilados e vistos de maneira conjunta. A Ecologia é uma área que atrai muitos alunos também por envolver atividades práticas, sobretudo, de campo, motivando e resultando em um bom aprendizado.

Tabela 1: Áreas em que os alunos se sentem "mais" preparados para trabalhar como professores.

\begin{tabular}{lc}
\multicolumn{1}{c}{ Áreas } & \% de indicação \\
\hline Ecologia & 14,9 \\
Genética & 14,9 \\
Zoologia & 10,4 \\
Botânica & 9,0 \\
Microbiologia & 9,0 \\
Anatomia & 7,5 \\
Biologia celular & 6,0 \\
Evolução & 4,5 \\
Bioquímica & 4,5 \\
Parasitologia & 4,5 \\
Biotecnologia & 4,5 \\
Educação ambiental & 3,0 \\
Etnobiologia & 1,5 \\
Didática & 1,5 \\
Bioestatística & 1,5 \\
Biologia molecular & 1,5 \\
Gestão ambiental & 1,5 \\
\hline
\end{tabular}

O mesmo pode ser afirmado para a área de Genética, pois para o bom entendimento desta são necessários conhecimentos de áreas como Biologia Celular, Biologia Molecular, Bioquímica e Estatística, indicando ser também uma área que conta com uma gama de informações e possibilita a interdisciplinaridade. Atividades práticas são também vivenciadas na Genética, o que é observado em grande parte no âmbito dos laboratórios, resultando em um aprendizado eficaz e possibilitando um maior preparo dos alunos.

Nesse contexto, Kato e Krasilclick (2011) destacam que atividades acadêmicas que levam os alunos a fazerem associações entre os conteúdos contribuem para um maior aprendizado, o que reforça a importância e a necessidade de se trabalhar a interdisciplinaridade no âmbito do ensino superior. Com isto, destaca-se o quanto é importante o professor enriquecer sua aula com assuntos que levam a pensar sobre um fato ou uma problemática de forma contextualizada e sistemática.

A terceira área de maior indicação foi a Zoologia. É comum nos cursos de Ciências Biológicas os alunos apresentarem um grande interesse por essa área, o que muitas vezes é apontado como o motivo que os fizeram ingressar no curso. A Zoologia tendo sido uma das áreas mais apontadas leva ao entendimento que existe, entre os alunos pesquisados, uma grande preferência pelo estudo dos animais, o que é contemplado em diversas disciplinas ao longo do curso.

Os cursos de nível superior apresentam assim um grande papel na formação profissional, levando os alunos a serem formados e se sentirem seguros para trabalhar em uma determinada área. Dessa forma, disciplinas, professores, ementas, conteúdos, cargas horárias e atividades complementares apresentam uma grande influência no perfil do profissional que será formado (MENDES, 2006).

Contudo, a identificação desse perfil nos alunos não deve ser realizada apenas ao final do curso, mas sim, ao longo da ocorrência deste. A partir da identificação da aptidão, o professor poderá ampliar a visão de ciência para esse aluno, desenvolvendo estratégias que possibilitem engaja-lo na área e trabalhar os conteúdos de maneira a transformar sua realidade educacional (VASCONCELOS; LIMA, 2009).

Os alunos citaram também áreas como Botânica, Microbiologia, Anatomia e Biologia Celular como aquelas em que estes também se sentem preparados. Dessa forma, vê-se que o curso levou a uma boa formação em diversas áreas, o que inclui a área animal, vegetal, ambiental e molecular, fato esse 
comprovado pela variedade de citações apresentadas pelos alunos.

Ao indagar os alunos sobre as áreas para as quais os mesmos se sentem "menos" preparados, foi possível obter os resultados presentes na Tabela 2. Esses resultados indicam áreas em que provavelmente os alunos não gostariam de trabalhar, pois, uma vez em que estes não se sentem preparados, a tendência é evitar o contato com as mesmas e, principalmente, a exposição no que diz respeito a ministrar aulas sobre.

Tabela 2: Áreas em que os alunos se sentem "menos" preparados para trabalhar como professores.

\begin{tabular}{ll} 
preparados para trabalhar como professores. \\
\hline Breas & \% de indicação \\
\hline Zoolonica & 19,4 \\
Ecologia & 14,9 \\
Genética & 9,0 \\
Bioquímica & 9,0 \\
Anatomia & 7,5 \\
Fisiologia humana & 6,0 \\
Biofísica & 4,5 \\
Fisiologia vegetal & 4,5 \\
Evolução & 4,5 \\
Didática & 3,0 \\
Embriologia & 3,0 \\
Histologia & 3,0 \\
Espermatófitas & 3,0 \\
Etnobiologia & 3,0 \\
Microbiologia & 1,5 \\
Bioestatística & 1,5 \\
\hline
\end{tabular}

Ao observar as áreas mais citadas pelos alunos identifica-se que áreas que antes tinham sido apontadas por alguns alunos como as de "maior" preparo foram apontadas por outros como as de "menor" preparo, o que se aplica à Botânica, Zoologia, Ecologia e Genética. Esses resultados mostram que essas áreas apresentam características particulares em que, ou os alunos assimilam seus conteúdos a ponto de se sentirem preparados para dar aulas sobre seus assuntos, ou apresentam uma rejeição para com as mesmas a ponto de afirmarem que não estão preparados para das aulas sobre seus temas.

Nesse contexto é viável destacar que o ensino dessas áreas deve ser realizado de forma a atrair os alunos, os levando a estar minimamente preparados para ministrarem aulas. Para isto é necessário que, independente da área, os conteúdos teóricos sejam abordados de forma a serem associados com a prática, buscando uma compreensão do contexto geral de sua aplicação, o que pode se dá com base em intervenções para a construção do conhecimento (MCKENNEY; REEVES, 2013).

O fato da Botânica ter sido a mais indicada nesse contexto, requer ainda uma investigação adicional, a qual vai fornecer explicações do porquê a porcentagem de indicação foi tão expressiva para essa área quando comparada às demais. Um provável motivo para isto é a vastidão de conteúdos que precisam ser estudados para que a Botânica seja bem compreendida, o que, por vezes, se torna um fator cansativo e desestimulador dos alunos.

Como os conteúdos das Ciências Biológicas são considerados base para outras ciências (ARAÚJO, 2014), o aprendizado não pode ser realizado de maneira superficial. Ao considerar que após formados, os alunos podem se submeter a trabalhar em qualquer área, uma grande responsabilidade é atribuída àqueles que apresentam o papel de formadores, os quais devem ter atenção quanto as áreas em que os alunos apresentam deficiências.

É necessário ainda que além da formação conteudista, o ensino de Biologia converta para uma formação da consciência crítica dos alunos, oferecendo a estes informações e correlações próprias da área (SILVA, 2013). Para isto, os alunos devem construir os conhecimentos a partir do desenvolvimentos de atividades práticas integrativas, valorizando a 
especificidade de cada setor de estudo e a conexão entre esses (SILVA; LANDIM, 2012).

Algo que também chamou a atenção nessa pesquisa foi que entre as áreas citadas nas duas categorias ("maior" e "menor" preparo), as maiores indicações foram para áreas próprias das Ciências Biológicas, não contando com indicações expressivas da área pedagógica, mesmo se tratando de um curso de licenciatura. Apesar da grande aptidão demostrada pelos alunos por uma determinada área, vale a pena ainda indagar se estes realmente apresentam um preparo do que diz respeito a ser professor.

A Didática, por exemplo, como área de "menor" preparo foi citada por 3\% dos alunos, e como área de "maior" preparo, foi citada por apenas 1,5\% destes. Essa informação se soma ao fato desta área ter sido a única do campo pedagógico indicada, à qual é vivenciada em disciplinas dentro do curso e necessita ser aplicada na prática em momentos como os estágios supervisionados que acontecem na reta final da formação destes alunos.

Situações como estas fazem com que as disciplinas pedagógicas acabem cumprindo o mero papel de complementação das disciplinas biológicas ou específicas (ROCHA, 2013). Com isto, torna-se urgente que os professores ao ensinar sobre um determinado tema, não apenas transmitam o conhecimento, mas ajudem os alunos a construí-lo, de forma que estes sejam aptos à transmiti-lo à outro.

\section{CONCLUSÃO}

Conclui-se com essa pesquisa que as diferentes áreas de estudo devem ser igualmente fortalecidas no que diz respeito à formação dos alunos, não havendo deficiências que possam comprometer o desempenho, ou mesmo o interesse pelo que está sendo estudado. A adoção de estratégias diferenciadas pode, nesse contexto, ser um auxiliador ao processo de ensino-aprendizagem, devendo principalmente as aulas práticas serem inseridas no ensino sempre que possível.

Apesar de se buscar um aprofundamento em uma determinada área, os alunos não devem esquecer que para ser professor precisam dominar também o aspecto pedagógico da profissão, o qual deve ser incorporado em todas as situações possíveis. Pesquisas dessa ordem orientam alunos e professores sobre lacunas que podem ser resolvidas ao longo do processo, resultando em profissionais que realizarão seu trabalho com excelência e qualidade.

\section{REFERÊNCIAS}

Ábila F. Inovação na Educação. Revista Aprendizagem. 2010;2:34-39. Disponível em: https://revista.unitins.br/index.php/humanida deseinovacao/article/view/67

Araújo WS. Ensino de Biologia: Relação dos conteúdos com o cotidiano do aluno. In: Congresso Nacional de Educação; 2014. Disponível em: <http://www.editorarealize.com.br/revistas/co nedu/trabalhos/Modalidade_

1datahora_11_08_2014_13_44_47_idinscrito_3 2370_4d9cedb092e511fc27a73fa8d9d72bc7.pdf >. Acesso em: 10 out. 2017.

Barros AJS, Lehfel NAS. Fundamentos de Metodologia Cientifica. 3nd. ed. São Paulo: Prentice-hall; 2007.

Cevallos I. O mestrado profissional em ensino de matemática e o desenvolvimento profissional de professores: um desafio institucional [Tese] São Paulo: Pontifícia Universidade Católica de São Paulo; 2011. Disponível em: https://sapientia.pucsp.br/handle/handle/1087 4

Charlot B. Relação com o saber, formação dos professores e globalização: questões para a educação hoje. Porto Alegre: ArtMed; 2005.

Imbernón F. Inovar o ensino e a aprendizagem na Universidade. São Paulo: Cortez; 2012. 
Kato DS, Kawasaki CS. As concepções de contextualização do ensino em documentos curriculares oficiais e de professores de ciências. Ciência \& Educação. 2011;17:35-45. Disponível em:

http://www.scielo.br/pdf/ciedu/v17n1/03.pdf

Lakatos EM, Marconi MA. Metodologia científica. 6nd. ed. São Paulo: Atlas; 2011.

Marcelo C. Desenvolvimento profissional docente: passado e futuro. Ciências da Educação. 2009;8:7-22. Disponível em: http://www.unitau.br/files/arquivos/category_ 1/MARCELO_Desenvolvimento_Profissional _Docente_passado_e_futuro_1386180263.pdf

McKenney S, Reeves TC. Systematic review of design based research progress: Is a little knowledge a dangerous thing? Educational researcher. 2013;42:97-100. Disponível em: https:/ /doi.org/10.3102/0013189X12463781

Mendes RPR. Percepção sobre meio ambiente e educação ambiental: o olhar dos graduandos de ciências biológicas da PUC-BETIM [Dissertação] Belo Horizonte: Universidade Católica de Minas Gerais; 2006. Disponível em: http://www.biblioteca.pucminas.br/teses/Educ acao_MendesRP_1.pdf

Morin E. A cabeça bem-feita. Repensar a reforma, reforma o pensamento. 21nd. ed. Rio de Janeiro: Bertrand Brasil; 2014.

Morin E. Os sete saberes necessários para a educação do futuro. 2nd. ed. São Paulo: Editora Cortez; 2015.

Pinto UA. Pedagogia Escolar: coordenação pedagógica e gestão educacional. São Paulo: Cortez; 2011.
Prodanov CC, Freitas EC. Metodologia do trabalho científico: Métodos e Técnicas da Pesquisa e do Trabalho Acadêmico. 2nd. ed. 2. Rio Grande do Sul: Universidade FEEVALE; 2013.

Rocha LD. Avaliação do curso de licenciatura em ciências biológicas da UNIFAL-MG na perspectiva de seus egressos. Revista Profissão Docente. 2013;13:76-98. Disponível em: http://www.revistas.uniube.br/index.php/rpd/ article/view/568

Silva ML. A Importância do Ensino Contextualizado na Biologia. 2013. Disponível em: http://www.nead.fgf.edu.br/novo/material/m onografias_biologia/MARIA_LUCILENE_DA _SILVA.pdf

Silva TS, Landim MF. Aulas práticas no ensino de Biologia: Análise da sua utilização em Escolas no município de Lagarto/SE. 2012. Disponível em: http://educonse.com.br/2012/eixo_06/PDF/ 5.pdf

Teixeira FM, Sobral ACMB. Como novos conhecimentos podem ser construídos a partir dos conhecimentos prévios: um estudo de caso. Ciência \& Educação. 2010;16:667-677. Disponível em: https://dialnet.unirioja.es/servlet/articulo?codi go $=5274339$

Vasconcelos SD, Lima KEC. Envolvimento em atividades extra classe, avaliação do curso e perspectivas de licenciandos em Biologia da Universidade Federal de Pernambuco. Revista Brasileira de Pesquisa em Educação em Ciências. 2009;9:50-69. Disponível em: https://periodicos.ufmg.br/index.php/rbpec/a rticle/view/3995 